\title{
DETERMINATION OF THE FRACTURE TOUGHNESS OF POLYCARBONATE USING AN ENERGY APPROACH
}

\author{
Hiro Uete and Robert M. Caddell \\ Department of Mechanical Engineering and Applied Mechanics, The University of Michigan, \\ Ann Arbor, MI 48109, U.S.A.
}

(Received 11 November 1981; in revised form 19 April 1982)

\begin{abstract}
Summary-A number of polycarbonate (PC) specimens, having the same compact tension type configuration but with different initial crack lengths, was tested at $-12^{\circ} \mathrm{C}$ under Mode I type loading. The pop-in loads and corresponding displacements at the loading pins were plotted and connected by a common curve. The value of $K_{I C}$ was determined using the method first proposed by Gurney and Hunt and was in close agreement with values reported by others. It is concluded that the pop-in load versus displacement curve is equivalent to a locus describing crack propagation under plane-strain conditions and suggests a new approach for determining $K_{I C}$ for ductile solids.
\end{abstract}

$A$ crack area

NOT ATION

dA change in crack area

$a$ crack length

$\mathrm{d} a$ change in crack length

$a_{0}$ initial crack length

$E$ modulus of elasticity

$G_{c}$ critical strain-energy release rate

$K_{I C}$ critical plane-strain stress intensity factor

$k$ specimen stiffness

$P$ boundary load

$P_{1,2}$ boundary load at a specific displacement

$\boldsymbol{R}_{g}$ fracture toughness per Gurney-Hunt

$t$ specimen thickness ( $B$ in ASTM nomenclature)

$u$ total displacement

$\mathrm{d} u$ change in displacement

$u_{1,2}$ displacement at a specific load

$\Lambda$ strain energy

$\mathrm{d} \Lambda$ change in strain energy

$\nu$ Poisson's ratio

$W$ length of specimen from loading line

\section{INTRODUCTION}

Gurney and Hunt[1] proposed a method to determine fracture toughness during quasi-static crack propagation that is based upon an energy balance and is referred to here as the Gurney method. This provides an alternative to the more widely used method currently standardized by ASTM [2] and has been substantiated as to reliability where brittle solids are concerned. The question addressed in this paper is whether the Gurney approach could be used in situations where plane-stress effects cannot be considered to be negligible.

The phenomenon of "pop-in" has been discussed by Boyle et al.[3] and Key and Katz [4] who suggested that this occurrence is connected with plane-strain fracture. To our knowledge, no one heretofore has attempted to combine the pop-in phenomenon and the Gurney approach. The use of PC and a test temperature of $-12^{\circ} \mathrm{C}$ were chosen to ensure that there would be sufficient plastic deformation to belie fully brittle failure yet not so much that excessive plastic flow would predominate the cracking process. Also, a literature search indicated that any viscous effects at this temperature during the short time interval of a test would be negligible.

Since the technique suggested by this paper differs from any used previously, it is 
crucial to explain the difference, and give a brief discussion of earlier studies. Apparently, Boyle et al.[3] were the first to discuss pop-in and they suggested that the values of $K_{N C}$ (their nomenclature) based upon pop-in loads were similar in magnitude to $K_{I C}$ determined under plane-strain conditions. Assuming this was true, test specimens much thinner than those required for plane-strain tests could be used to determine $K_{I C}$. This would be of great importance since, for many materials, inordinately thick specimens are needed to cause a condition of plane strain in such tests. Using three different type specimens of 7075-T6 aluminum they determined values of $K_{N C}$ using various equations for $K_{N C}=(P / t) f(a / w)$ of the form now widely used in fracture mechanics analyses. Although they found a difference between $K_{N C}$ values using edge-notched versus center-notched specimens, the concept that pop-in seemed connected with plane-strain behavior was a significant one.

Key and Katz[4] pursued this idea using polycarbonate (PC) as a test material. Single edge-notch specimens of $6.3 \mathrm{~mm}(1 / 4 \mathrm{in}$.) thickness were tested at room temperature and loaded at a rate of $0.2 \mathrm{~cm} / \mathrm{min}(0.033 \mathrm{~mm} / \mathrm{s})$. Two types of fracture were observed; one was of the pop-in type whereas the second displayed a flat or square crack front and catastrophic failure. They suggested that certain "critical" thicknesses of the specimen provided a dividing line as to whether pop-in or catastrophic failure was likely to occur. Their most significant finding was that the load associated with pop-in was the same as the load that was reached just prior to catastrophic failure. The latter type of failure surface was of a plane strain nature so it appeared that pop-in might be equivalent to a plane-strain condition as suggested earlier [3]. A value of $K_{I C}=3.29 \mathrm{ksi} \cdot V$ (in.) $(3.16 \mathrm{MPa} \cdot V(\mathrm{~m}))$ was indicated for PC, tested at room temperature [4].

Other studies with $\mathrm{PC}$ have reported the value of $K_{I C}$ to range from 2.2 to $3.2 \mathrm{MPa} \cdot V(m)[5-8]$ at a temperature around $-12^{\circ} \mathrm{C}$; none of these emphasized the phenomenon of pop-in when determining $K_{I C}$. The spread of values above undoubtedly arises from the use of different specimen configurations and testing conditions (loading rate and temperature), but most of these reported values were towards the upper end of the range (i.e. 3.2 MPa $\cdot V(m)$ ). In one of those Ref. [6], the combined findings of [6-8] were compared by plotting $K_{I C}$ versus temperature. At $-12^{\circ} \mathrm{C}$, as used in our work, the values for $K_{I C}$ ranged from 2.8 to $3.15 \mathrm{MPa} \cdot V(m)$. Note that in all of those studies, such values were calculated from various equations used in fracture mechanics. With this background, the technique employed in our work will now be discussed and will be shown to be different from any used previously.

\section{THEORY}

Gurney's concept, which is fully discussed elsewhere [9], is presented in its essentials here since it has received relatively little attention, especially in the United States. Considering an energy balance for fully reversible behavior (i.e. at any time during crack propagation, an unloading of the testpiece would follow a load-displacement trace back to the origin; see Fig. 1)

$$
P d u=d \Lambda+R_{g} \mathrm{~d} A
$$

where: $P=$ boundary load; du $=$ displacement at the loading pins; $\mathrm{d} \Lambda=$ change in strain energy; $R_{g}=$ fracture toughness per Gurney (note: $R$ was used originally. To avoid possible confusion with $R$-curve analyses, $R_{g}$ is used here); and $d A=$ change in crack area. In essence, the external work $(P d u)$ is equated to strain energy and the energy consumed to propagate the crack.

Referring to Fig. 1, let the various areas below line $B L M H$ be designated as follows:

$$
I=O L u_{1}, I I=O M u_{2}, I I I=u_{1} L M u_{2}, I V=O L M .
$$

During the load drop from $L$ to $M$, the crack propagates by a length $d a$ and if the specimen thickness is $t$ (i.e. $B$ in the ASTM designation [2]) then eqn (1) implies,

$$
I I I=(I I-I)+(I V)
$$

such that the sector area $O L M$ represents the term $R_{g}(t d a)$. Such a simple graphical analysis is truely one of the powers of this approach to fracture toughness. As discussed elsewhere [9], if the trace between $L$ and $M$ is close to a straight line (small intervals will always permit this) then 


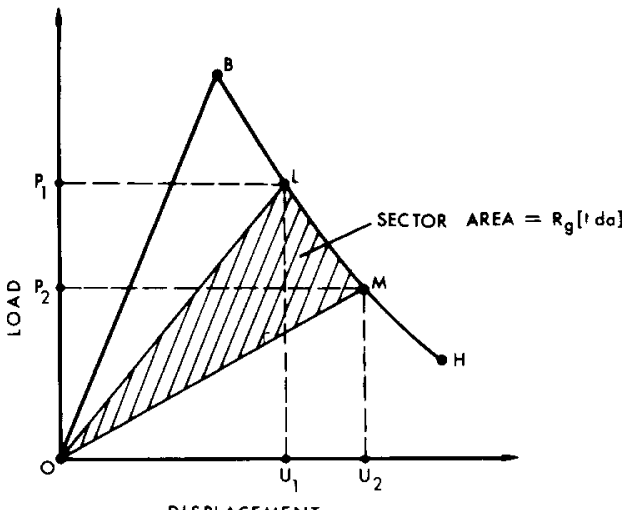

FIG. 1. General $P$ - $u$ plot for quasi-static crack propagation showing how fracture toughness, $R_{R}$, is related to a sector area.

$$
R_{g}=1 / 2\left[P_{1} u_{2}-P_{2} u_{1}\right] /(t d a) .
$$

Another advantage here is that a number of measures of $R_{g}$ can be made from a single test. Since $R_{g}$ is basically equivalent to the strain energy release rate, $G_{c}$ at the onset of crack propagation, (see Ref. [9]) it can be related to $K_{I C}$ via,

$$
K_{I C}^{2}=\frac{E R_{g}}{1-\nu^{2}} \quad \text { (plane strain) }
$$

or

$$
K_{i C}^{2} \approx E R_{g}
$$

if the Poisson effect were neglected. See [9] for details.

\section{EXPERIMENTAL WORK}

Test specimens of PC were made from commercial sheets of $6.3 \mathrm{~mm}(1 / 4 \mathrm{in}$.) thickness. Although the final specimen dimensions are shown in Fig. 2, a procedure was followed to produce a "starting" crack shape as close to "natural" as possible. Oversized specimens were first machined and the initial crack was produced with a sharp milling cutter. These were loaded on an Instron machine in an environmental chamber stabilized at $-12^{\circ} \mathrm{C}$. Initial crack propagation here was usually quite fast but was subsequently arrested. These specimens were then unloaded and machined to the size shown in Fig. 2 with the one variable now being the "starting crack length", $a_{0}$. This was produced by removing excess material from the oversized specimens. In all, seven test specimens were made with starting crack lengths varying from 51 to $85 \mathrm{~mm}$.

For each test, the temperature was stabilized using a combination of dry ice, liquid $\mathrm{CO}_{2}$ and a special nozzle adapted to an Instron environmental chamber. A fan, inside the chamber, provided forced air circulation and measurements indicated the temperature variation to be within $\pm 1{ }^{\circ} \mathrm{C}$ when a "stable" condition was obtained. The machine crosshead speed was $0.05 \mathrm{~cm} / \mathrm{min}(8.33 \mu \mathrm{m} / \mathrm{s})$ for all tests. Each of the specimens was then loaded and a load-displacement trace recorded.

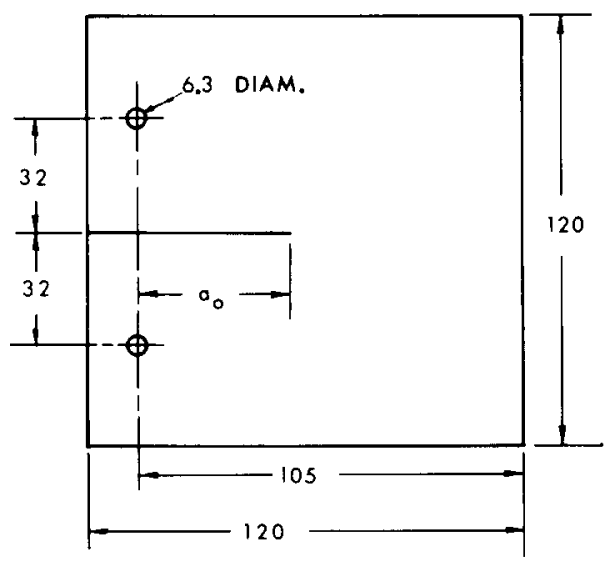

Fig. 2. Test specimen where all dimensions are in $\mathrm{mm}$. 


\section{COMMENTS ON SPECIMEN STIFFNESS OR COMPLIANCE}

Since it is essential for a correct energy analysis, and because improper assumptions could be made in this regard, the stiffness of test specimens was studied. By stiff ness we refer to the linear portion of the initial load-displacement trace prior to pop-in; in essence, the stiffness, $k$, equals $P / u$. Initially, a specimen similar to that in Fig. 2 was made by sawing a starting crack length of $50 \mathrm{~mm}$. The specimen was then loaded in tension to produce the desired $P_{-} u$ trace. After unloading, the starting crack length was increased $5 \mathrm{~mm}$ by sawing, reloaded to give the new $P-u$ trace and again unloaded. This was continued by increasing the crack length in $5 \mathrm{~mm}$ increments up to a starting length of $80 \mathrm{~mm}$. The results are shown as $A$ in Fig. 3 .

The stiffnesses of the seven test specimens, whose "natural" starting crack lengths were discussed in Section 3, were also determined. These are plotted as $B$ on Fig. 3 and as seen, they differ from the curve obtained from the specimens having starting cracks made by saw cuts. Because of this difference, no further reference is made to curve $A$, but this does point out the need to use the correct stiff ness per starting condition of the initial crack. This discussed further in the next section.

\section{RESULTS}

Fig. 4 is a schematic representation of the type of load-displacement behavior that results when pop-in is followed by crack propagation accompanied by large plastic flow; note that unloading does not cause a return to the origin. Fig. 5 is a schematic illustration of a series of such curves where the starting crack length varies. By picking the load and displacement at pop-in and plotting these combinations on the appropriate loading line, a series of points such as $L, M$ and $N$ results. Connecting such points by a best-fit curve then produces a locus that describes events related to pop-in. Fig. 6 presents actual experimental points used in this manner. Once the "best-fit" line was drawn, the stiffness for starting "natural" cracks lengths from 50 to $80 \mathrm{~mm}$ (in increments of $5 \mathrm{~mm}$ ) were found from curve $B$ on Fig. 3. These were drawn to

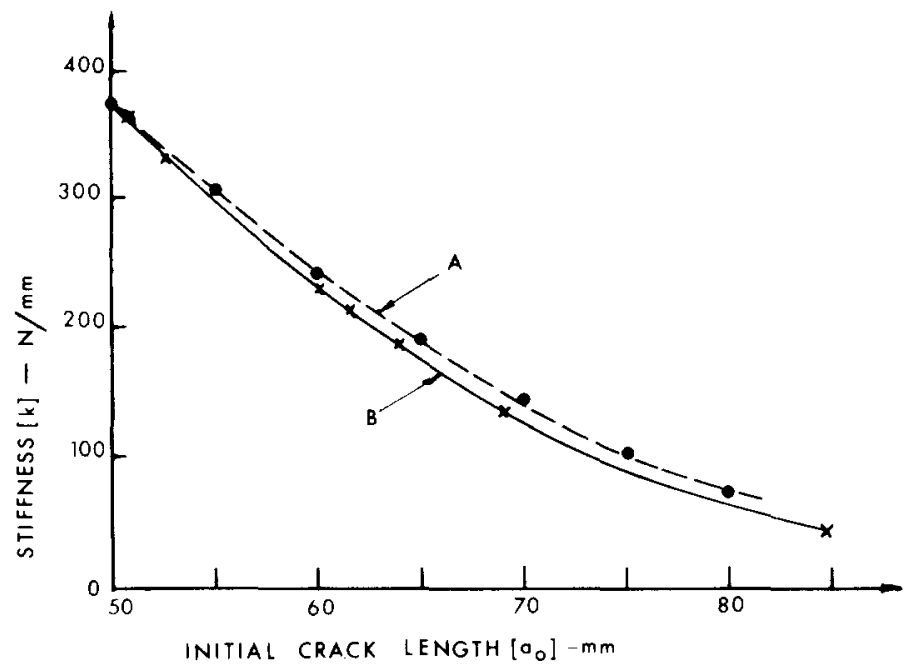

FIG. 3. Specimen stiffness, $k$, versus starting crack length for initial cracks made by saw cuts $(A)$ and for "natural" sharp starting cracks $(B)$.

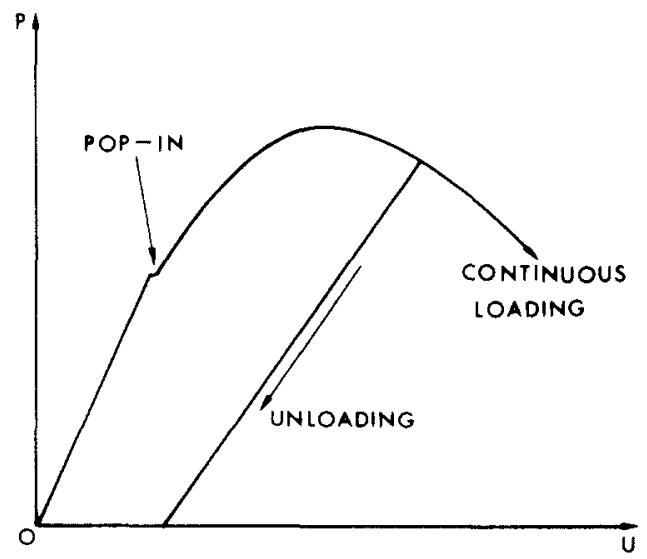

FIG. 4. Typical $P$ - $u$ behavior of a ductile material illustrating "pop-in" and irreversibility upon unloading. 


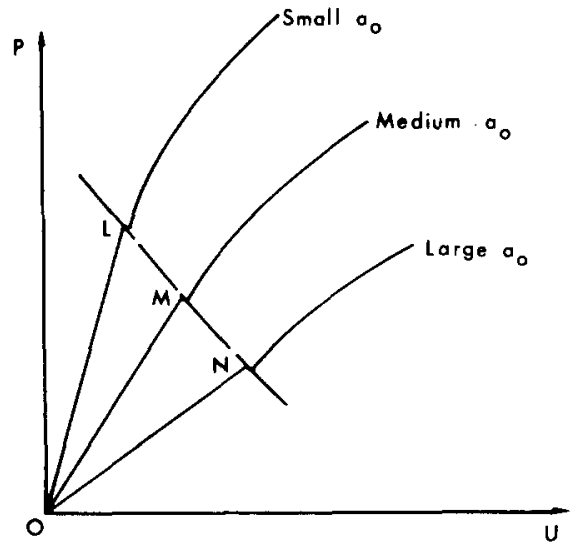

FIg. 5. Typical $P-u$ behavior of a ductile material with different starting crack lengths; a common curve connects the pop-in points $L, M$ and $N$.

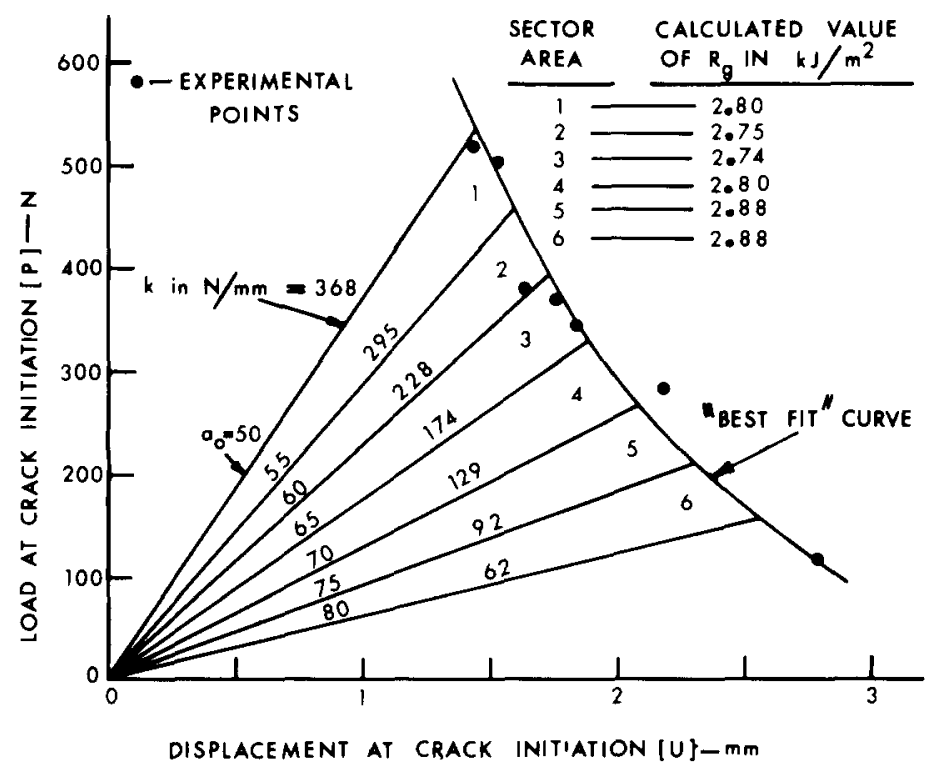

FIG. 6. Determination of $\boldsymbol{R}_{g}$ using points of intersection from varying stiffness lines and the best-fit curve of experimental points. See Table 1 for the $P$ and $U$ values used to compute $R_{q}$.

scale as shown in Fig. 6 and the $P$ and $u$ values at the intersection of these stiffness lines with the experimental curve are tabulated in Table I. On Fig. 6, six sector areas result and by using eqn (3), six values of $R_{g}$ were determined; they ranged from 2.74 to $2.88 \mathrm{~kJ} / \mathrm{m}^{2}$, the average being $2.81 \mathrm{~kJ} / \mathrm{m}^{2}$. A separate tension test (using a standard type tensile specimen) was made using a calibrated extensometer and two transverse sensors. The elastic modulus was found to be $2.8 \mathrm{GPa}$ while Poisson's ratio was 0.40 . From equation (4) the average value of $K_{I C}$ was calculated as $3.06 \mathrm{MPa} \cdot V(m)$.

Table 1. Data used to determine $\boldsymbol{R}_{\mathrm{g}}$ as taken from Fig. 6

\begin{tabular}{|c|c|c|c|}
\hline \multirow{2}{*}{$\begin{array}{l}\text { Initial } \\
\text { Crack } \\
\text { Length } \\
\left(a_{0}\right)-m m\end{array}$} & \multirow{2}{*}{$\begin{array}{l}\text { Stiffness } \\
\text { For Crack } \\
\text { Length } \\
(\mathrm{k})-\mathrm{N} / \mathrm{mm}\end{array}$} & \multicolumn{2}{|c|}{$\begin{array}{l}\text { Values of load and } \\
\text { displacement for inter- } \\
\text { section points of differing } \\
\text { stiffness lines and the } \\
\text { "best fit" curve of } \\
\text { experimental points }\end{array}$} \\
\hline & & $\mathrm{P}-\mathrm{N}$ & $\mathrm{u}-\mathrm{mm}$ \\
\hline $\begin{array}{l}50 \\
55 \\
60 \\
65 \\
70 \\
75 \\
80\end{array}$ & $\begin{array}{r}368 \\
295 \\
228 \\
174 \\
129 \\
92 \\
62\end{array}$ & $\begin{array}{l}534.5 \\
460.9 \\
392.3 \\
328.5 \\
269.7 \\
210.8 \\
156.9\end{array}$ & $\begin{array}{l}1.45 \\
1.58 \\
1.72 \\
1.88 \\
2.08 \\
2.30 \\
2.57\end{array}$ \\
\hline
\end{tabular}




\section{CONCLUSIONS}

Using the Gurney concept in combination with pop-in loads and displacements leads to values of $K_{I C}$ for polycarbonate that are in excellent agreement with published data obtained using other techniques. This suggests a new approach for determining the plane-strain fracture toughness of solids that fracture under combined plane-strain, plane-stress effects and may preclude the need for using specimens whose thickness is currently "standardized" according to ASTM specifications [2].

Acknowledgement-The authors thank Prof. W. F. Hosford for his helpful comments.

\section{REFERENCES}

1. C. Gurney and J. Hunt, Proc. Royal Soc. London A299, 508-524 (1967).

2. ASTM Annual Book of Standards, E399-74, Part 10, pp. 432-451 (1974).

3. R. W. Boyle, A. M. Sullivan and J. M. KRaFFT, Welding J. 41, 428-s-432 (1962).

4. P. L. KEY and Y. KATZ, Int. J. Fracture Mech. 5, 63-68 (1969).

5. M. Parvin and J. G. Williams, J. Matl's Sci. 10, 1883-1888 (1975).

6. R. Ravetti, W. W. Gerberisch and T. E. Hutchinson, J. Matl's. Sci. 10, 1441-1448 (1975).

7. A. P. Glover, F. A. Johnson and J. C. Radon, Poly. Engng Sci. 14, 420-428 (1974).

8. P. L. Key, Y. KATZ and E. R. PARKer, UCRL-17911, Lawrence Radiation Lab, U. of Cal., Berkeley (Feb. 1968).

9. R. M. CADDELl, Deformation and Fracture of Solids, pp. 205-207, 224-233, 238-239. Prentice-Hall, Englewood Cliffs, New Jersey (1980). 